\title{
Low-temperature smoothing method of scalloped DRIE trench by post-dry etching process based on $\mathrm{SF}_{6}$ plasma
}

\author{
Jin Soo Park ${ }^{1,2}$, Dong-Hyun Kang ${ }^{3}$, Seung Min Kwak³ ${ }^{3}$ Tae Song Kim¹, Jung Ho Park², Tae Geun Kim², \\ Seung-Hyub Baek ${ }^{4}$ and Byung Chul Lee ${ }^{1 *}$ (i)
}

\begin{abstract}
Deep reactive-ion etching (DRIE) is commonly used for high aspect ratio silicon micromachining. However, scalloping, which is the result of the alternating Bosch process of DRIE, can cause many problems in the subsequent process and degrade device performance. In this work, we propose a simple and effective method to smoothen the scalloping of DRIE trenches. The proposed method utilizes sidewall dry etching by reactive-ion etching (RIE) based sulfur hexafluoride $\left(\mathrm{SF}_{6}\right)$ plasmas, following the DRIE process. To investigate the effect of the etch parameter on the scallop smoothing effect, the radio frequency (RF) power and gas flow are controlled. After the RIE treatment, the scallop smoothing effects were evaluated by measuring the average scallop depth under each condition. The scallop depth was reduced by $91 \%$ after implementing the scallop smoothing technique using RIE. Thus, our smoothening method based on $\mathrm{SF}_{6}$ plasmas would provide broad availabilities and applicability in silicon micromachining with the simple low-temperature process.
\end{abstract}

Keywords: Deep reactive-ion etching, Reactive-ion etching, SF 6 plasma, Scallop smoothing, Silicon micromachining

\section{Introduction}

Deep reactive-ion etching (DRIE) is the most popular dry etching process used to create deep trenches and holes for various applications such as micromachining of micro-electromechanical systems (MEMS) and throughsilicon via (TSV) for three-dimensional (3D) packaging [1]. The DRIE process is known as the Bosch process steps that are pulsed and time-multiplexed etching. In the Bosch process, the etching and passivation steps are alternating to achieve vertical trenches [2]. However, the repeated etch/deposit steps in DRIE essentially create scalloped sidewalls in trenches, and this degrades the performance of MEMS devices. For example, the scalloped sidewall of silicon can cause degrade the

\footnotetext{
*Correspondence: bclee@kist.re.kr

${ }^{1}$ Center for BioMicrosystems, Korea Institute of Science and Technology,

Seoul 02792, Republic of Korea

Full list of author information is available at the end of the article
}

performance of silicon diodes by introducing interface charge and undesired capacitance [3]. In addition, the scalloping of silicon sidewalls causes light scattering and reduces the signal-to-noise ratio (SNR) in optical applications such as micromirrors, silicon waveguide, and optical switches [4-6].

To address these problems, many studies have developed strategies to fabricate scallop-free silicon structures in micromachining. The initial studies focused on the direct modification of the DRIE processes. Voss et al. modified the DRIE processes by introducing $\mathrm{C}_{4} \mathrm{~F}_{8}$ and $\mathrm{O}_{2}$ gases during the etching process [3]. The incorporation of $\mathrm{C}_{4} \mathrm{~F}_{8}$ in each etching step resulted in smooth profiles; however, the etch rate of silicon was low. Chen et al. increased the ion flux density using a higher coil power during the etching to reduce the passivation removal time [7]. The decrease in the switching time between the etch and passivation steps reduced the scalloping. Another strategy to fabricate scallop-free trenches is incorporating 
other etch systems. Fu et al. employed reactive-ion etching (RIE) as the DRIE assistant based on aspect ratio dependent scalloping attenuation (ARDSA) effect in the Bosch process [8]. RIE and the subsequent deposition of a thick passivation layer preceded the DRIE process to avoid the scalloped sidewall at the top of the trenches while using DRIE at increasing trench depth. Compared with the conventional DRIE process, the RIE-combined DRIE process could reduce the scalloped sidewall roughness by approximately $60 \%$. However, chipmakers cannot directly modify DRIE systems in many cases because the DRIE process is often optimized for other production purposes. Besides, incorporating other etching systems to DRIE can complicate the overall etching process for vertical trench fabrications complicated.

Alternatively, other researchers have explored strategies to smoothen the scalloped DRIE sidewalls via postprocessing, without modifying the DRIE process. Focused ion beam (FIB) milling techniques for optical MEMS devices were investigated by Song et al. [9]. The FIB milling technique effectively reduced the RMS value of the sidewall roughness below $10 \mathrm{~nm}$. However, FIB milling is not suitable for mass production because trenches are treated one at a time, making it timeconsuming. Zishan et al. developed a DRIE roughness reduction method based on alternating oxidation and oxide removal steps [10]. This method is based on the fact that the oxidation rate of the sharp silicon tip of scalloped sidewalls is higher than that of other regions. Repeated oxidation and oxide removal cycles can reduce the scallop depth of trenches from $410 \mathrm{~nm}$ to $80 \mathrm{~nm}$. However, high-temperature oxidation at $965{ }^{\circ} \mathrm{C}$ can cause heatrelated problems such as severing the metal connection of integrated circuits (ICs) in direct fabrication of MEMS devices on the substrate with ICs.

In this study, we proposed a simple and effective scallop smoothing method using dry etching, RIE. The RIE with single $\mathrm{SF}_{6}$ gas flow smoothens the scalloped DRIE trenches. This smoothening effect can be controlled by selecting the physical and chemical etching conditions of the $\mathrm{SF}_{6}$ plasmas. The proposed method employs lowtemperature $\left(<200{ }^{\circ} \mathrm{C}\right)$ dry etching. Also, the use of the single $\mathrm{SF}_{6}$ gas, rather than a mixture gas, can reduce the complexity of etching, thereby reducing the cost of the process during mass production.

\section{Materials and methods}

Silicon cylindrical trenches with a diameter of $70 \mu \mathrm{m}$ and a height of $230 \mu \mathrm{m}$ were the target structures to investigate the proposed scallop smoothing method. Figure 1

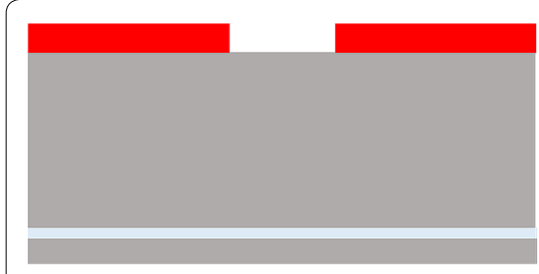

a

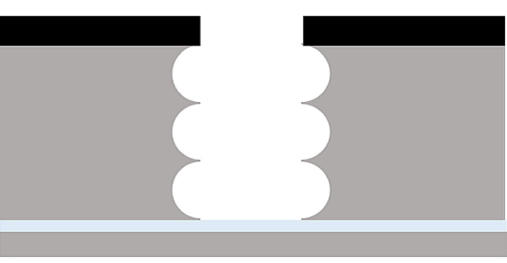

d

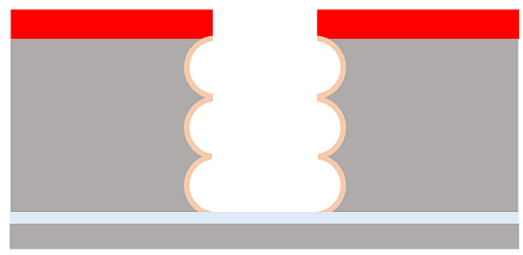

b

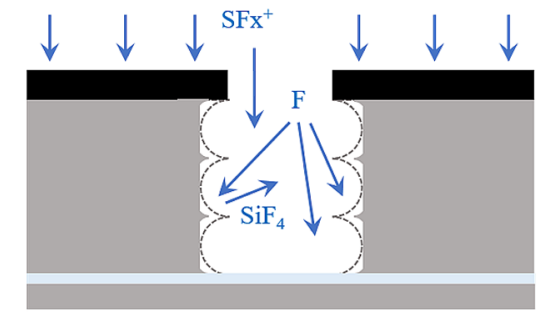

$\mathbf{e}$

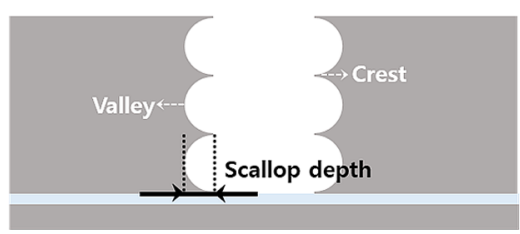

c

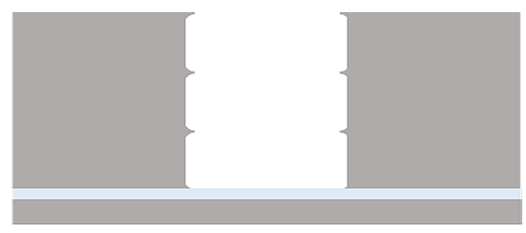

f

$\mathrm{Si}$

Photo resist

Passivation layer $\mathrm{SiO}_{2}$

Fig. 1 Experimental process of scallop smoothing of DRIE trench by RIE-based $\mathrm{SF}_{6}$ plasmas. This process flow represents a single trench of $64 \times 8$ arrays. a Patterning the photoresist with a circular pattern mask on the silicon handle layer of an SOI wafer. $\mathbf{b} 230 \mu \mathrm{m}$ deep DRIE of the silicon handle layer. (c) Removing the photoresist on the surface of the handle layer and ashing the passivation layer on the sidewall of the trench. $\mathbf{d}$ Transferring black ink onto the silicon surface for masking the surface. e Scallop smoothing using subsequent RIE. f Final smoothened trench after cleaning the black ink 
shows a schematic diagram of the overall experimental processes. First, the circular $64 \times 8$ arrays were patterned on the silicon handle layer of a silicon on insulator (SOI) wafer (Buysemi, Seoul, Republic of Korea) via standard photolithography (Fig. 1a). The thicknesses of the silicon device layer and the silicon handle layer of the SOI wafer were $5 \mu \mathrm{m}$ and $230 \mu \mathrm{m}$, respectively. The buried oxide (BOX) layer, which acts as the DRIE etch stopper, had a thickness of $1 \mu \mathrm{m}$ thick. Negative photoresist, DNR-L300-40 (Dongjin Semichem Co., Ltd., Seoul, Republic of Korea), was spin-coated on the SOI handle layer with a thickness of $5.4 \mu \mathrm{m}$, providing sufficient hard mask during the DRIE of $230 \mu \mathrm{m}$. After patterning the circular arrays with the negative photoresist using an MA6 mask aligner (Suss Microtec SE, Garching, Germany), we used an Omega ${ }^{\circledR}$ LPX-DSi Etch system (SPTS Technologies Ltd., Newport, United Kingdom) to etch the handle silicon by the cyclic Bosch process (Fig. 1b). The etched trenches had an aspect ratio of approximately 3:1. Before the subsequent RIE for scallop smoothing, the patterned photoresist and sidewall passivation layer formed during the deposition steps of DRIE were removed using $\mathrm{O}_{2}$ plasma asher, Mini-Plasma Station (Plasmart Corp., Daejeon, Republic of Korea) (Fig. 1c). The ashing process was performed for $10 \mathrm{~min}$ at RF power of $350 \mathrm{~W}$ under 100 sccm $\mathrm{O}_{2}$ gas flow.

After ashing, the average scallop depths of the DRIE trenches were measured before scallop smoothing using RIE. Because the sample has a circular $64 \times 8$ array pattern, we diagonally cleaved the sample along the array pattern to view the cross-section of the trench using scanning electron microscopy (SEM). Two different locations, where the one is near the top area and the other is at the bottom of the trench, were selected to compare the smoothening effects statistically. Since the cleaving process can chip the weak top opening area, the scallops at approximately $50 \mu \mathrm{m}$ away from the top opening area were selected. We defined the scallop depth as the distance from the tangential line of the midpoint valley to the line passing in-between two adjacent crests (Fig. 1c). Every 5 ripples of the scallops were selected at each location in one dice sample, which means a total of 10 data points in the sample. We also collected the measured data with different 5-6 samples selected in random locations across the wafer.

One another wafer was selected from the DRIE wafer samples to apply the scallop smoothing RIE technique. This is to maintain a consistent exposed area and reduce the sample variation during the scallop smoothing RIE process. We covered and re-patterned the circular arrays with black ink transferred via a soft lithographic method to protect the surface of the wafer. A custommade $2 \mathrm{~cm} \times 2 \mathrm{~cm}$ square PDMS sheet was soaked into alcohol-based ink (Monami, Yong-in, Republic of Korea). After the PDMS sheet has sufficiently swelled, the ink was transferred to the wafer surface through contact with the PDMS sheet. We perfomed the hard bake procedure of the ink at $90{ }^{\circ} \mathrm{C}$ for $1 \mathrm{~min} 30 \mathrm{~s}$. Finally, the RIE process for scallop smoothing was performed (Fig. 1e) using a plasma etching system (PlasmaPro 800 Plus, Oxford Instruments Plasma Technology, Bristol, United Kingdom). The proposed scallop smoothing method utilizes $\mathrm{SF}_{6}$ plasmas. The process temperature was approximately $10{ }^{\circ} \mathrm{C}$, which can be beneficially applied to the fabrication process with a low thermal budget. The silicon crests have a higher probability of reacting with the incident $\mathrm{SF}_{x}$ ions and fluorine (F) radicals than the silicon valleys. The etch rate of the crest is higher than that of the valley, resulting in smooth sidewalls. After completing all the etch processes, the patterned black ink was removed by dipping in acetone and isopropyl alcohol (Fig. 1f). To achieve the most effective scallop smoothing of DRIE trenches, the etch parameters, $\mathrm{RF}$ power and $\mathrm{SF}_{6}$ flows, were mainly controlled. These variables regulate physical etching by ions and chemical etching by radicals in the plasma etching system [11]. By precisely tuning these parameters, we obtained the optimal etching condition for the proposed method to achieve scallop-free trenches.
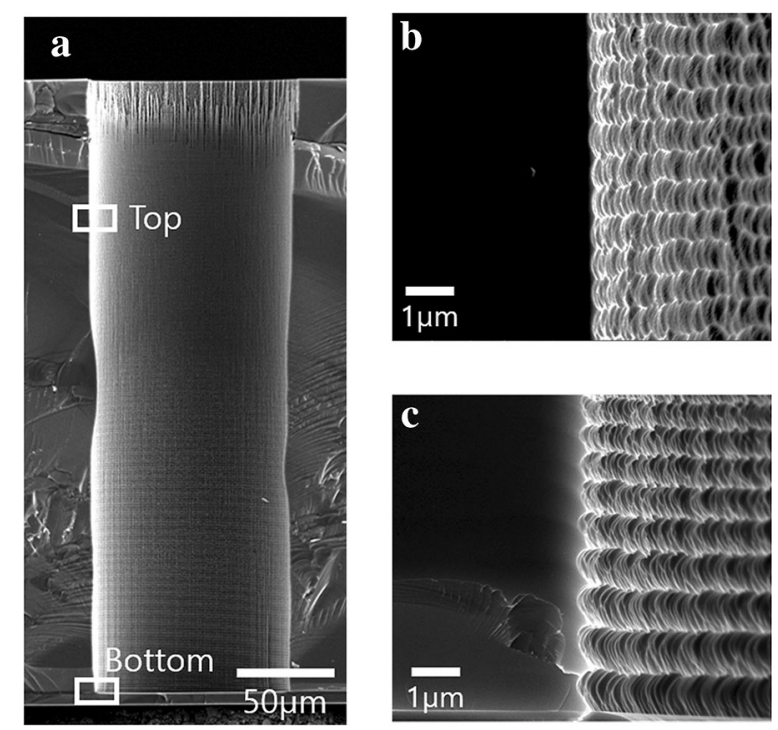

Fig. 2 Cross-section SEM images of a DRIE trench before scallop smoothing. a SEM image of the entire trench. Magnified SEM images of the sidewall (b) near the top area and (c) at the bottom of the trench 


\section{Results and discussion}

Figure 2 shows the cross-section SEM image of a typical DRIE trench. From Fig. 2b, c, it can be seen that the sidewall of the DRIE trench shows scalloping. The initial average scallop depths before scallop smoothing were $130 \mathrm{~nm}$ at the top and $230 \mathrm{~nm}$ at the bottom of the trench. The influence of the RF power on sidewall etching for scallop smoothing was investigated. We increased the RF power from $100 \mathrm{~W}$ to $250 \mathrm{~W}$ at intervals of $50 \mathrm{~W}$ and fixed other etch parameters such as pressure $(2$ mTorr), $\mathrm{SF}_{6}$ flow $(10 \mathrm{sccm})$, and process time $(10 \mathrm{~min})$. Figure $3 \mathrm{a}$ shows the measured average scallop depths under each RF power condition. The scallop depth at the top of the trench decreased with an increase in the
RF power. As noted by Tzeng, increasing the RF power considerably increases the concentrations of both $\mathrm{F}$ radicals and ions [12]. The increased physical and chemical reaction by the radicals and ions etched the silicon crests more quickly than the valleys of the sidewalls; therefore, smoother sidewalls can be achieved (Fig. 3b). However, at the bottom of the trench, the average scallop depth increased slightly at $150 \mathrm{~W}$. It can be observed from Fig. 3c that an angled sidewall profile was formed when the RF power increased above $150 \mathrm{~W}$. The slope of the scalloped sidewall formed an angle of $\sim 64^{\circ}$ with the surface plane (Fig. 4a), and this morphology is related to the crystal orientation. The angled sidewall profiles were formed by secondary etching of the reflected ions during

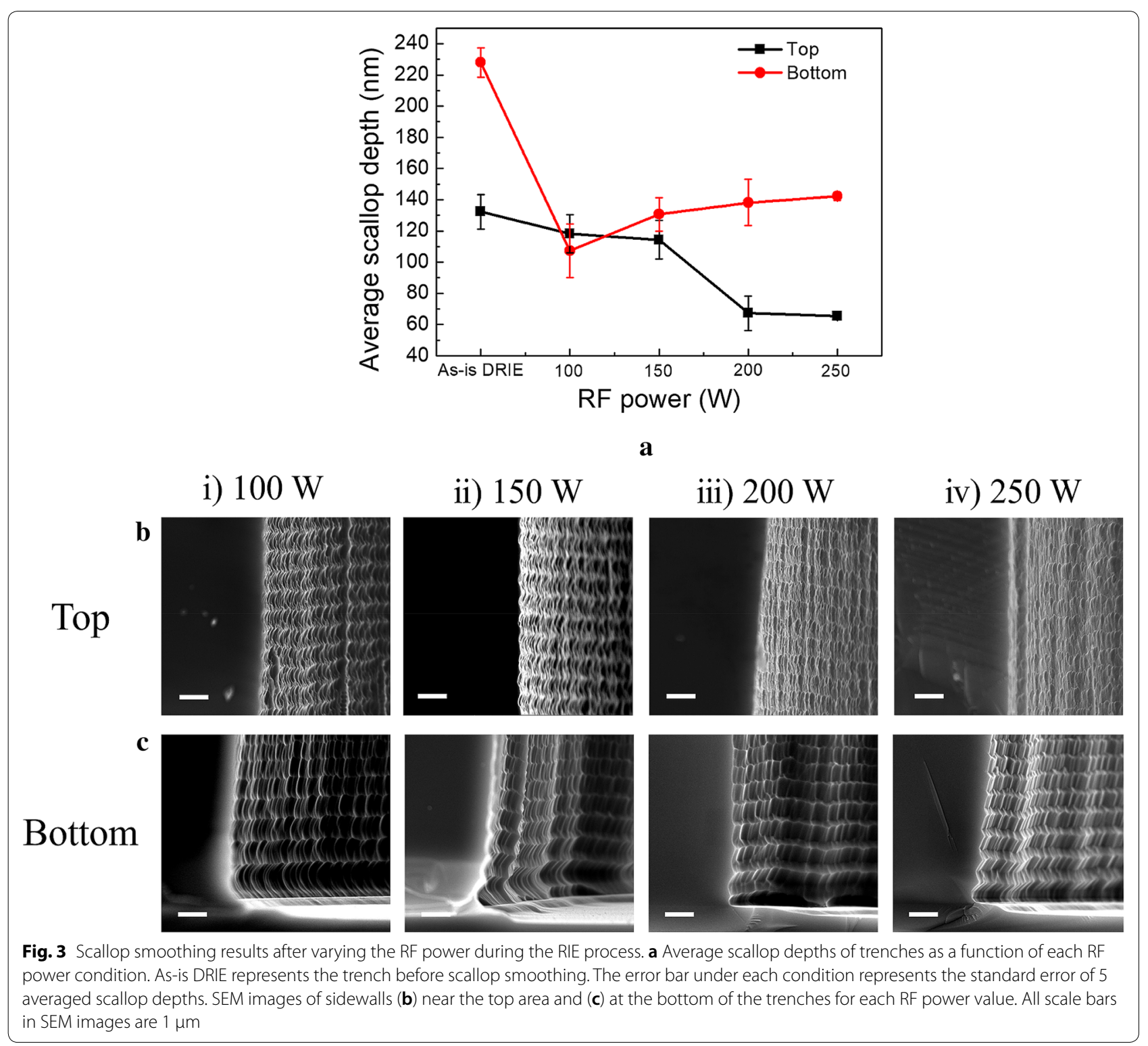




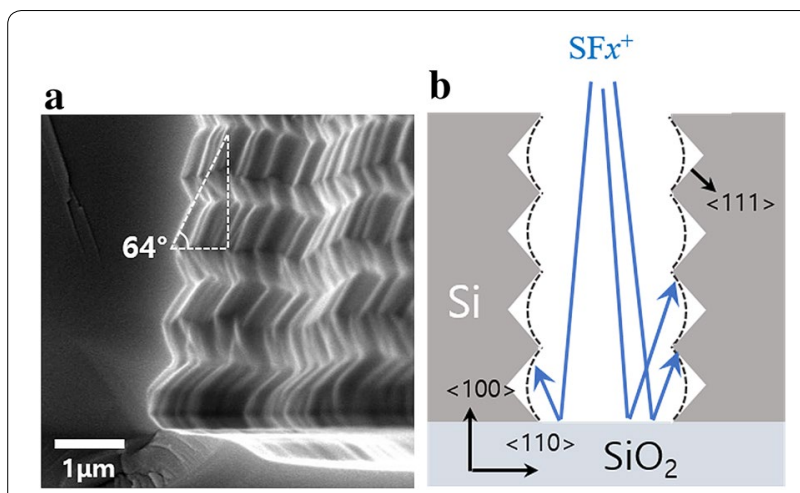

Fig. 4 a The magnified SEM image of Fig. 3c-iv. b Illustration of angled sidewall scallop formation by impingement of secondary ions

silicon plasma etching. The difference in the etch rates in a different direction in silicon results in the appearance of $<111>$ crystal planes; the sidewall profiles form angles of $50-70^{\circ}$ with the surface plane [13]. As the RF power increased, the increase in the self-bias voltage accelerated more $\mathrm{SF}_{x}$ ions to the bottom surface of the trenches, forming more angled sidewall profiles [11]. These excited $\mathrm{SF}_{x}$ ions bounced back to further distances from the surface of the BOX layer. The impingement of the reflected ions etched the sidewall anisotropically, resulting in angled and sharp scalloped sidewalls (Fig. 4b). Varying the RF power did not produce the desired scallop smoothing effect on the bottom side to reduce the average scallop depth of the entire trenches, owing to the formation of angled sidewalls.

In order to investigate the influence of $\mathrm{SF}_{6}$ gas flow on sidewall smoothing, the $\mathrm{SF}_{6}$ flow rate was increased from $10 \mathrm{sccm}$ to $50 \mathrm{sccm}$. Other conditions, excluding RF power, were identical to those in the RF power variation. The RF power was fixed at $100 \mathrm{~W}$, where the scallop

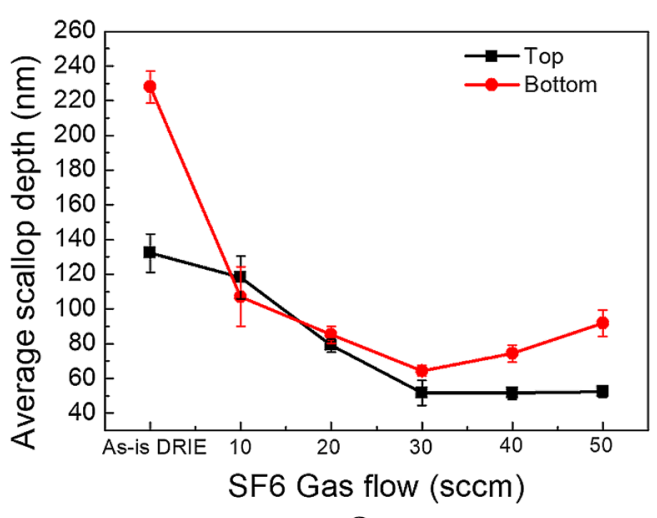

a

i) $10 \mathrm{sccm}$
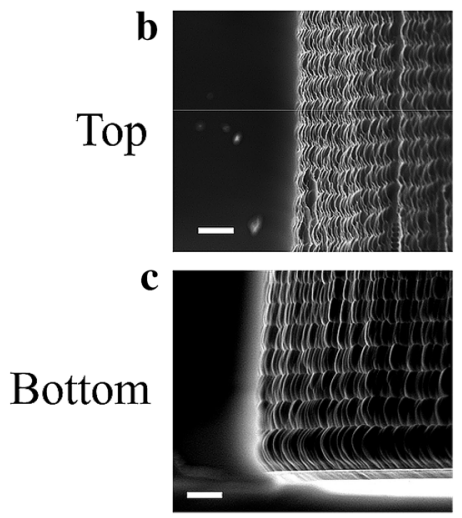

ii) $20 \mathrm{sccm}$
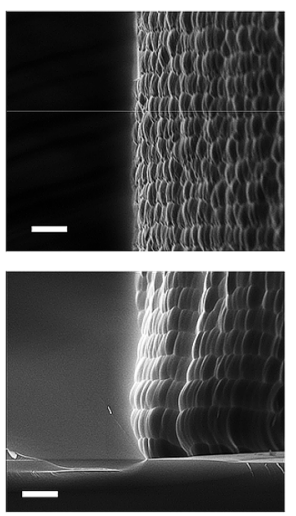

iii) $30 \mathrm{sccm}$
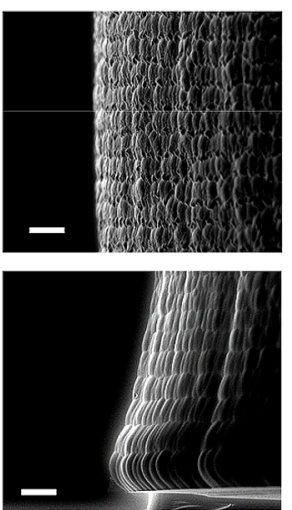

iv) $40 \mathrm{sccm}$
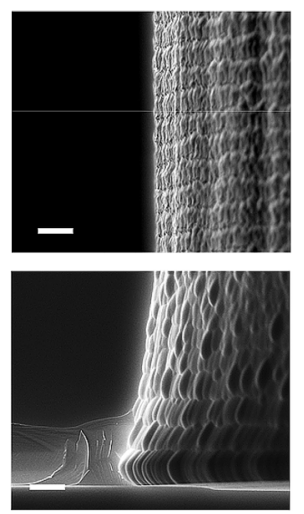

v) $50 \mathrm{sccm}$

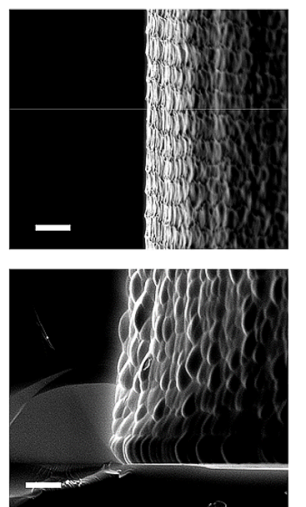

Fig. 5 Influence of the $\mathrm{SF}_{6}$ gas flows in the scallop smooting RIE process. a Average scallop depths of trenches as a function of each $\mathrm{SF}_{6}$ flow condition. As-is DRIE represents the trench before scallop smoothing. The error bar under each condition represents the standard error of 5 averaged scallop depths. SEM images of sidewalls $(\mathbf{b})$ near the top area and $(\mathbf{c})$ at the bottom of the trenches under each $\mathrm{SF}_{6}$ flow condition. All scale bars in SEM images are $1 \mu \mathrm{m}$ 
depth was reduced most effectively without the formation of an angled sidewall profile at the bottom of the trench. As shown in Fig. 5a, the average scallop depth at the top of the trench decreased with an increase in the gas flow rate. A higher $\mathrm{SF}_{6}$ flow increased the $\mathrm{F}$ radical concentration. This accelerated the chemical etching of the silicon crest, resulting in more smoothened profiles of sidewalls (Fig. 5b). At $\mathrm{SF}_{6}$ gas flow of $30 \mathrm{sccm}$, the scallop depth near the top area decreased by $70 \mathrm{~nm}$ from $130 \mathrm{~nm}$ to $60 \mathrm{~nm}$. On the other hand, the scallop depth at the bottom decreased by $160 \mathrm{~nm}$ from $230 \mathrm{~nm}$ to $70 \mathrm{~nm}$. This is because the higher vertex or larger exposed area of the scallop crest has a higher possible contact with the $F$ radical in order to etch away faster, which increases the etch rate. However, at the bottom, the average scallop depths increased when the $\mathrm{SF}_{6}$ flow was greater than $30 \mathrm{sccm}$. Irregular dented patterns were observed at the sidewalls at $40 \mathrm{sccm}$ and $50 \mathrm{sccm}$ (Fig. $5 \mathrm{c}$-iv and $\mathrm{c}-\mathrm{v})$. The factors responsible for these phenomena are not fully understood, but we assumed that a byproduct of etching is deposited irregularly during sidewall scallop smoothing. The chemical reaction between the $\mathrm{F}$ atoms and the $\mathrm{SiO}_{2}$ bottom surface can produce $\mathrm{SiO}_{x} \mathrm{~F}_{y}$, and this byproduct was deposited on the sidewall of trenches, inhibiting uniform sidewall scallop smoothing. According to previous studies, the inhibition by re-deposition of this byproduct increases the surface roughness or formation of silicon micro grass [14, 15]. Further research is necessary to correctly identify the factors responsible for these phenomena, which we believed to be due to the reaction mechanism between $\mathrm{SiO}_{2}$ and $\mathrm{F}$ radicals.

To avoid etching of the sidewall with dented patterns, the $\mathrm{SF}_{6}$ flow rate was fixed at $30 \mathrm{sccm}$, where the most significant scallop smoothing effects were observed without dented patterns. The RF power and pressure conditions were set to $100 \mathrm{~W}$ and 2 mTorr, respectively. Increasing the etching time to $30 \mathrm{~min}$ resulted in smoother sidewalls of DRIE trenches. Figure 6 shows the cross-sectional SEM images of the trench smoothened at $\mathrm{SF}_{6} 30 \mathrm{sccm}$ for $30 \mathrm{~min}$. No scallops were visible on the sidewall near the top of the trench. The average value of the scallop depth decreased below $20 \mathrm{~nm}$ (91\% reduction from $230 \mathrm{~nm}$ ), without any dented patterns or angled sidewall scalloping at the bottom of the trench (Fig. 6b). Since the long etching time of the scallop smoothing RIE process can widen the circular trench, it is necessary to investigate the opening diameters of the trench before

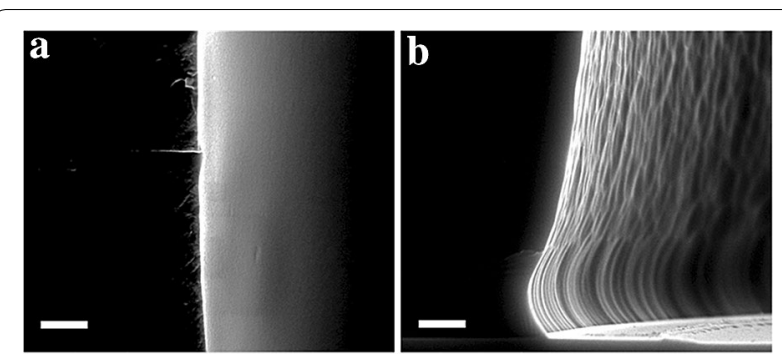

Fig. 6 Cross-sectional SEM images of DRIE trench smoothened using the optimized RIE condition of $100 \mathrm{~W}$ RF power and $30 \mathrm{sccm} \mathrm{SF}_{6}$ flow for $30 \mathrm{~min}$. Cross-sectional SEM images of the sidewall (a) near the top and (b) at the bottom of the trench. All scale bars in SEM images are $1 \mu \mathrm{m}$

and after performing the smoothening technique. As shown in Fig. 7a, b, the diameter of the top area slightly increased from $70.17 \mu \mathrm{m}$ to $72.68 \mu \mathrm{m}$ (a $1.25 \mu \mathrm{m}$ increase in the radius) after $30 \mathrm{~min}$ of scallop smoothing RIE. Since an excessive number of cycles in the DRIE process etched the BOX layer of the SOI wafer, size expansion at the bottom can be measured by inspecting the annular residual pattern, as shown in Fig. 7 d. A subsequent RIE etching process, in which the selectivity between silicon and silicon oxide is very high, removed only the sidewall of the silicon, resulting in the horizontal expansion of the annular borderline of the silicon. This residue of the buried oxide layer was shown as an annular pattern at the edge of the trench. The width of the annular pattern was $1.49 \mu \mathrm{m}$, indicating an increment in the radius at the bottom of the trench.

\section{Conclusion}

In this study, we proposed a simple and effective smoothing method of scalloped DRIE trenches using dry etching. There were no heat-related problems and risk of damaging the IC in the substrate as the method employs low-temperature dry etching. Furthermore, the use of $\mathrm{SF}_{6}$ single gas reduced the complexity of the etching system and the cost. By moderately controlling $\mathrm{SF}_{6}$ gas flows, the average scallop depth was reduced by $91 \%$ from $230 \mathrm{~nm}$ to $20 \mathrm{~nm}$ at the bottom of the trenches, resulting in smooth profiles of the sidewall trench. This method is expected to be useful for the manufacture of various MEMS devices that require smooth silicon trenches. 

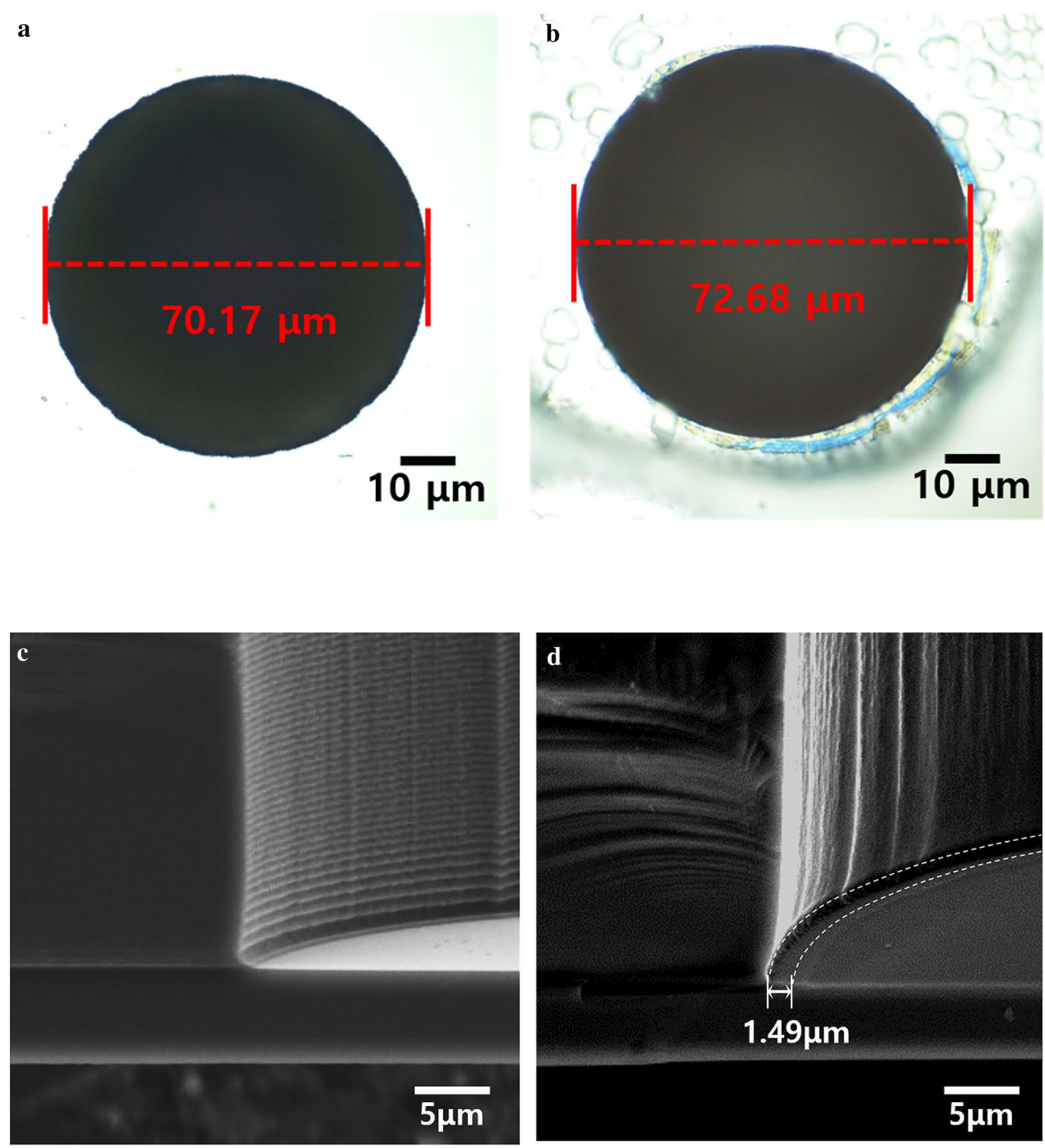

Fig. 7 Optical top view images of the opening trenches (a) before and (b) after the scallop smoothing RIE. Cross-sectional SEM images at the bottom of the trenches (c) before and (d) after scallop smoothing RIE for $30 \mathrm{~min}$

\section{Abbreviations}

DRIE: Deep reactive-ion etching; RIE: Reactive-ion etching; $\mathrm{SF}_{6}$ : Sulfur hexafluoride; RF: Radio frequency; MEMS: Micro-electromechanical system;TSV: Through silicon via; SNR: Signal to noise ratio; ARDSA: Aspect ratio dependent scalloping attenuation; FIB: Focused ion beam; ICs: Integrated circuits; SEM: Scanning electron microscopy; F: Fluorine.

\section{Acknowledgements}

This work is supported by the PRIDE-UP program of the KIST internal project (Grant No. 2V06310) and Samsung Research Funding \& Incubation Center of Samsung Electronics under Project Number SRFC-MA1702-03. The entire fabrication processes, including DRIE and scallop smoothing RIE, were performed at KIST Micro-Nano Fabrication Center (Seoul, South Korea). 


\section{Authors' contributions}

JSP, S-HB and BCL devised the idea and designed the experimental processes. D-HK and SMK performed the DRIE process for the fabrication of silicon trenches. JSP and D-HK performed RIE for scallop smoothing that is the primary process of this project. TSK, S-HB, and BCL supervised the project. JSP, $J H P, T G K$, and BCL analyzed the etching results of RIE for scallop smoothing. The first draft of the manuscript was written by JSP. All authors read and approved the final manuscript.

\section{Funding}

PRIDE-UP program of the KIST internal project (Grant No. 2V06310); Samsung Research Funding \& Incubation Center of Samsung Electronics (Project Number: SRFC-MA1702-03)

\section{Availability of data and materials}

The datasets supporting the conclusions of this article are included within the article.

\section{Competing interests}

The authors declare that they have no competing interests.

\section{Author details}

${ }^{1}$ Center for BioMicrosystems, Korea Institute of Science and Technology, Seoul 02792, Republic of Korea. ${ }^{2}$ Department of Electrical Engineering, Korea University, Seoul 02841, Republic of Korea. ${ }^{3}$ Micro-Nano Fabrication Center, Korea Institute of Science and Technology, Seoul 02792, Republic of Korea. ${ }^{4}$ Center for Electronic Materials, Korea Institute of Science and Technology, Seoul 02792, Republic of Korea.

Received: 19 May 2020 Accepted: 29 July 2020

Published online: 03 August 2020

\section{References}

1. Wu B, Kumar A, Pamarthy S (2010) High aspect ratio silicon etch: a review. J Appl Phys 108:9

2. Laermer F, Schilp A (1996) Method of anisotropically etching silicon. US Patent 5,501,893 26 Mar 1996

3. Voss LF, Shao A, Coway AM (2013) Smooth Bosch etch for improved Si diodes. IEEE Electron Dev Lett 34(10):1226-1228
4. Juan WH, Pang SW (1998) Controlling sidewall smoothness for micromachined Si mirrors and lenses. J Vac Sci Technol B 14:4080-4084

5. Morichetti F, Canciamilla A, Ferrari C, Torregiani M, Melloni A, Martinelli M (2010) Roughness induced backscattering in optical silicon waveguides. Phys Rev Lett 104:033902

6. Shoji Y, Kintaka K, Suda S, Kawashima H, Hasama T, Ishikawa H (2010) Low crosstalk $2 \times 2$ thermo-optic switch with silicon wire waveguides. Opt Express 18:9071-9075

7. Chen KS, Ayon AA, Zhang X, Spearing SM (2002) Effect of process parameters on the surface morphology and mechanical performance of silicon structures after deep reactive ion etching (DRIE). J Microelectromech Syst 11(3):264-275

8. Fu J, Li J, Yu J, Liu R, Li J, Wang W, Wang W, Chen D (2018) Improving sidewall roughness by combined RIE-Bosch process. Mat Sci Semicond Process 83:186-191

9. Song $\mathrm{IH}_{\text {, }}$ Peter YA, Meunier M (2007) Smoothing dry-etched microstructure sidewalls using focused ion beam milling for optical applications. J Micromech Microeng 17:1593

10. Mohammed ZAS, Olimpo MAS, Poenar DP, Aditya S (2017) Smoothening of scalloped DRIE trench walls. Mat Sci Semicond Proces 63:83-89

11. Legtenberg $R$, Jansen HV, de Boer M, Elwenspoek M (1995) Anisotropic reactive ion etching of silicon using $\mathrm{SF}_{6} / \mathrm{O}_{2} / \mathrm{CHF}_{3}$ gas mixtures. J Electrochem Soc 142(6):2020-2028

12. Tzeng $Y$, Lin TH (1987) Dry etching of silicon materials in $S_{6}$ based plasmas. J Electrochem Soc 134(9):2304-2309

13. Larsen KP, Petersen $\mathrm{DH}$, Hansen $\mathrm{O}$ (2006) Study of the roughness in a photoresist masked, isotropic, SF $_{6}$-based ICP silicon etch. J Electrochem Soc 153(12):1051-1058

14. Jansen $H$, de Boer M, Elwenspoek M (1996) The black silicon method. VI. High aspect ratio trench etching for MEMS applications. Proceedings of Ninth International Workshop on Micro Electromechanical Systems, p. 250-257

15. Jansen H, Gardeniers H, de Boer M, Elwenspoek M, Fluitman J (1996) A survey on the reactive ion etching of silicon in microtechnology. J Micromech Microeng 6(1):14

\section{Publisher's Note}

Springer Nature remains neutral with regard to jurisdictional claims in published maps and institutional affiliations.

\section{Submit your manuscript to a SpringerOpen ${ }^{\circ}$ journal and benefit from:}

- Convenient online submission

- Rigorous peer review

- Open access: articles freely available online

- High visibility within the field

- Retaining the copyright to your article

Submit your next manuscript at springeropen.com 